\title{
Research on Sustainable Design of Regeneration for Traditional Settlement Based on Ecotect Software
}

\author{
Hong $\mathrm{Xi}^{1 *}$, Ruiqiang Liu ${ }^{1}$, Weixiao Han ${ }^{1}$, Lei Zhang ${ }^{1}$ and Leilei Sun ${ }^{2}$ \\ ${ }^{1}$ School of civil engineering and architecture, Xi'an University of Technology, Xi' an, Shaanxi, 710048, China \\ ${ }^{2}$ School of Architecture, Soochow University, Suzhou, Jiangsu, 215123, China
}

\begin{abstract}
Based on the concept of sustainable protection and regeneration, this thesis retrospected and analysed the history and culture, public space and courtyard space of Miaohou village in Hancheng to explore the historical prototype. And combined with Ecotect Analysis software to simulate microclimate environment, the public spaces was reasonable updated and predicted from both qualitative and quantitative aspects to explore the rationalized strategy of rural renaissance. It will provide reference for the development of related construction practice and theory in the future.
\end{abstract}

\section{Foreword}

Traditional villages have a long history as human living space, highlighting the local culture and history. They are the invaluable cultural and historical legacy in China, and tourist resource as well ${ }^{1}$. The Guanzhong plain known as "800 li Qinchuan" of Shaanxi cultivated the morphologic prototype of the traditional rural settlements and left us with unique regional historical and cultural resources. Before reform and opening up, especially before 1949, most of traditional settlements of the rural town present a state of organic growth. Since the 1980s, with the rapid development of social economy and rapid urbanization, the traditional villages especially suburban ones have got a huge impact by the urban development. The slow pace of traditional settlements' development is completely changed. The social consciousness, life style, space form at all levels began to appear dissimilation phenomenon. For example, the internal order is changed, the traditional morphological structure tends to collapse, the traditional regional environments and cultural characteristics are declining rapidly ${ }^{2}$.

The public space of settlement, as the spatial carrier of rural production, life and ecology, is a vital part in rural development ${ }^{[3]}$. Especially in the urban fringe, the public space will produce a certain variation under the double effects of the thrust of urban expansion and the pull of rural internal development.

In this case, how to protect and inherit the cultural heritage in ancient villages furthest, and improve the public space effectively to achieve integration, symbiosis and sustainable development between urban and rural areas, has become an urgent problem to be solved. Ecotect software is a comprehensive sustainable design and analysis tool, including a wide range of simulation and analysis functions ${ }^{[4]}$. This paper, with the way of "Great to see small", tries to explore the rationalized strategy of rural renaissance through the research on the renewal and reconstruction of the public space of Miaohou village in Hancheng with the method of -field research and Ecotect simulation.

\section{Analyzing current investigation}

\subsection{Profile of the village}

Hancheng is a historic and cultural city in China with numerous traditional villages and the outstanding features of regional culture. The Miaohou village is located in northeast coast of the mid-Ju river in the South Gate of Han ancient city, adjacent to Han ancient city. It was the important trains to the ancient city connected city and town in the south, Shanxi in the east beside the village once ${ }^{[5-6]}$. The existing relatively complete settlement morphology is the typical "village and fort separated" settlement, with more traditional courtyards and buildings (Figure 1). However, as the surrounding urban renewal, the settlement is facing severe challenges. 


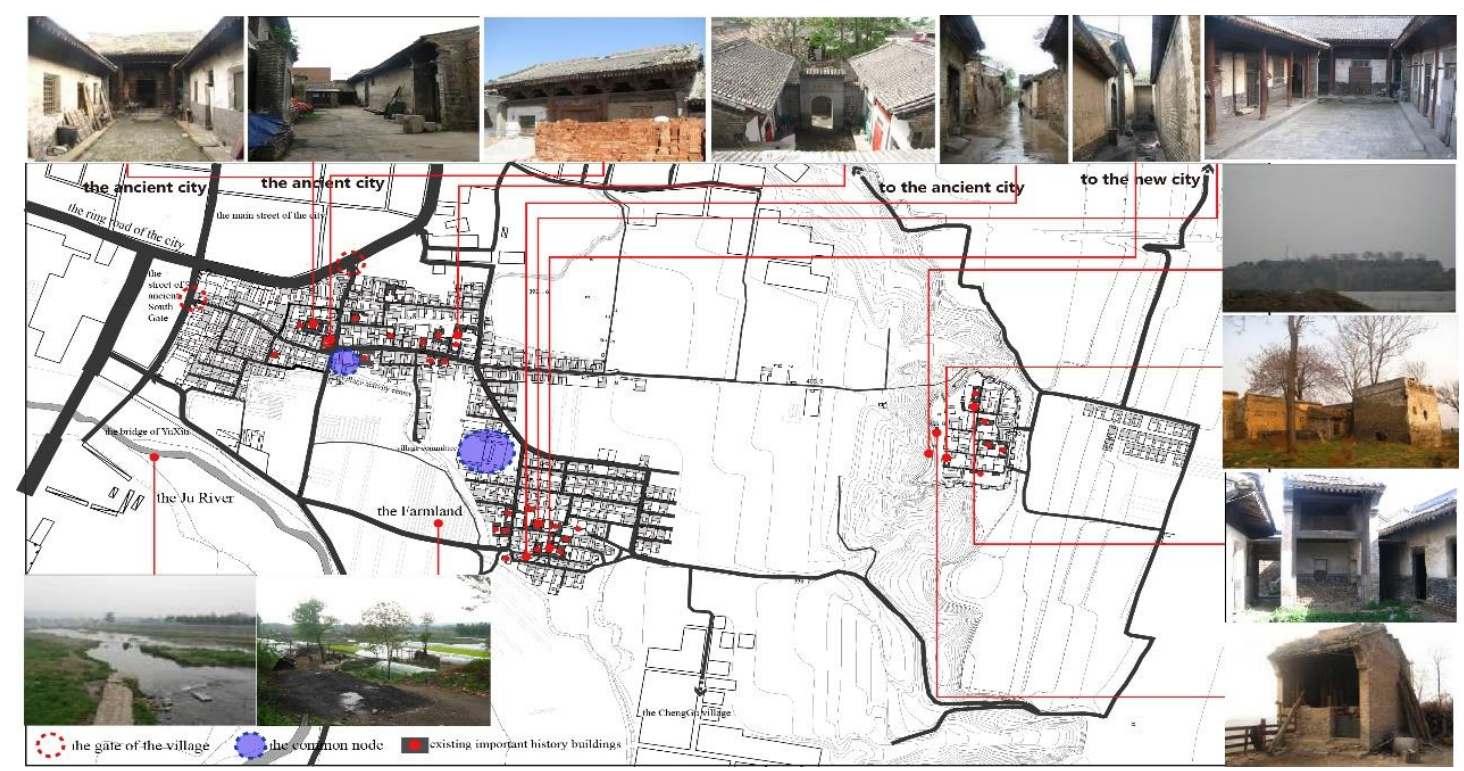

Figure 1. The sketch map of status quo and important historical building

In the practice of settlement renewal, it is necessary to pay attention to public space, overall texture and residential buildings [7] 。 In order to grasp the characteristics and existing problems of the overall public space, courtyard in Miaohou village intuitively and accurately, field research is an extremely important means of preliminary research. Based on the public space and courtyard, through field visit, questionnaire and mathematical statistics, the early stage comprehensively evaluated the historical evolution, functional types and current space feelings of the public activity space, meanwhile surveyed and analyzed the residential courtyard.

\subsection{The present situation of public space}

The investigation and analysis of the historical evolution of village public space show that in the peak period of Ming and Qing Dynasty, the community public space once had a variety of space such as ancestral temple, market, various sacrificial temples, theatrical stage, guard towers and so on. While influenced by different natural and political factors for hundreds of years, village committees, small shops have become the main public space. The only remaining few traditional public buildings are gradually abandoned, collapsed or demolished. On the whole, the number of public spaces was greatly reduced, and the function types tended to be single. Many spiritual spaces disappeared unable to meet the spiritual needs of the villagers, while also leading to weaken the cohesion of the settlements.

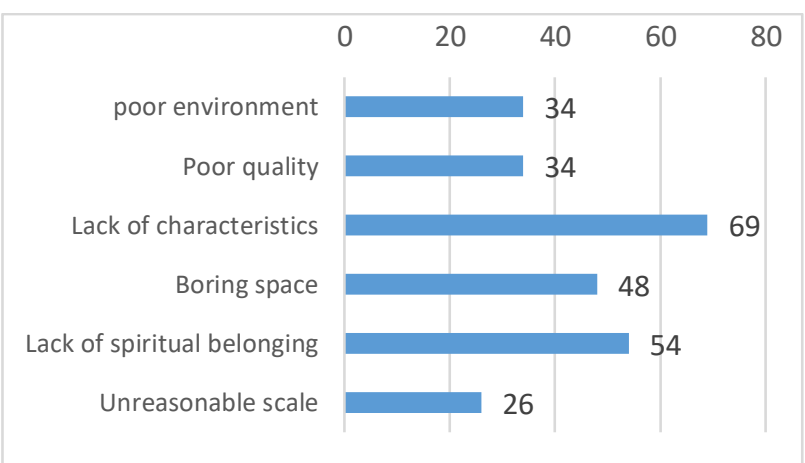

Figure 2. The questionnaire of existing problems of public space

The street intersection area near Erlang temple of the old village was originally the most important public activity center. The earliest theatrical stage, the wangs ancestral temple, Guanyin and Erlang temples were concentrated here before. In the subjective consciousness of the villagers, the area is still the public center of the whole village, which is the most suitable site for the design. However, according to the questionnaire (Figure 2 ), the villagers also showed great dissatisfaction with the current situation of the place and believed that it was in urgent need of renovation and renewal. About $81 \%$ of the villagers thought the existing buildings were in disorder, resulting in a lack of cultural identity. $64 \%$ of the villagers thought after the original religious building was demolished, the space lacked spiritual belonging. 56\% of the villagers thought space function was increasingly dull or boring after several changes. And about 30\% thought the quality of the environment and the space-experience were poor. Generally, the scope of core public centers is gradually reduced, cultural memory and historical characteristics are ignored, and space utilization rate is low.

\subsection{The present situation of courtyard}

According to the morphological characteristics, there are mainly five types of courtyards: "Quadrangles", "triple" 
shape, "L" shape, "U” shape and "口" shape. On this basis, data statistics were carried out for various types of institutes (Table 1).

Through the data analysis, it is found that the overall texture and scale of the courtyard are somewhat similar. Most of them are based on the traditional "Quadrangles". The average land scale is about $200 \mathrm{~m}^{2}$, among which the "triple" shape and "L" shape, account for a relatively large proportion. Meanwhile, the proportion of the wall height $(\mathrm{H})$ to the yard's width $(\mathrm{D} / \mathrm{H})$ of these two types of courtyard is relatively high. The results reflect residents' preference for the size and scale of the courtyard, which should be paid attention to in the design.

Table 1. Parametric analysis of spatial morphology of courtyard.

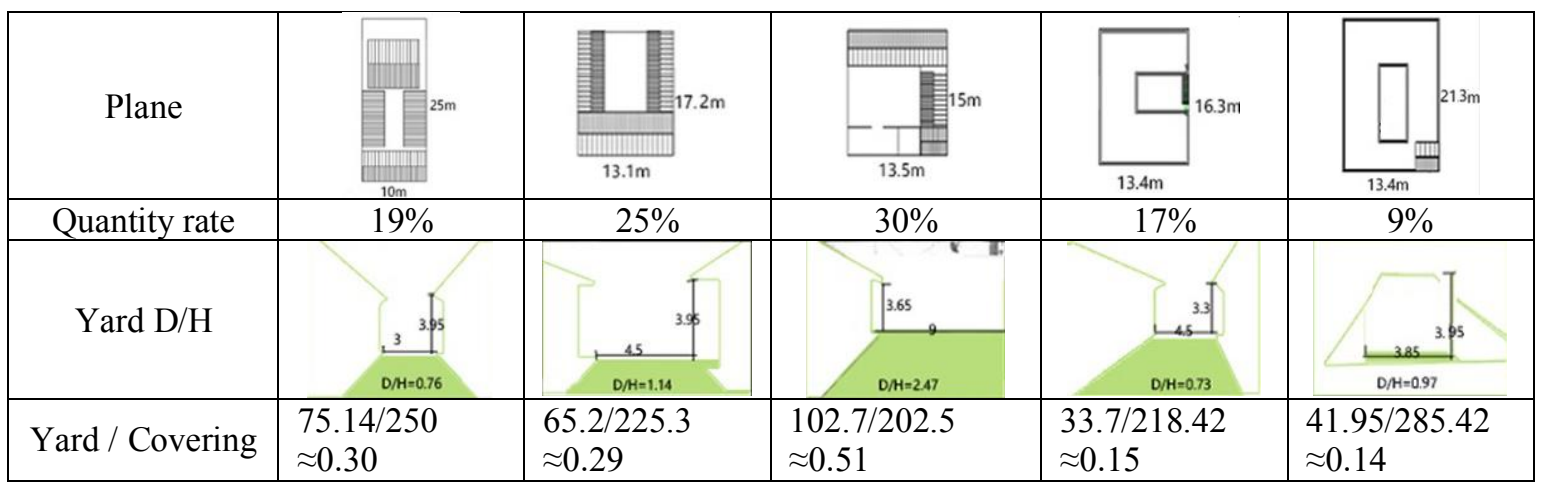

\section{Study on spatial renewal strategy}

\subsection{The whole design scheme}

Based on the systematic investigation and the software of Ecotect, the "integrity" updating strategy was formulated. About functional configuration of the public space, more consideration should be given to the continuation of the original spiritual attributes and varied spatial activities. The microclimatic environment of the building refers to the environment composed of the site and the indoor, which is most closely related to the functions and users ${ }^{[8]}$. For the micro-climate environment of the site, courtyard, the enclosed layout form has a great influence on that, as well as roof form and the proportion of yard. Therefore, about the forms of layout, it is necessary to adjust the layout so as to improve its overall microclimate environment on the basis of inheriting the traditional texture of the village.

\subsection{Building orientation}

Improving the rationality of building orientation without increasing the building cost can effectively improve the thermal performance ${ }^{[9]}$. According to the field research data, more than $80 \%$ of the courtyards in the village face south, which is related to the local terrain and geomantic customs. Meanwhile the relevant meteorological data were loaded into the Ecotect software for analysis with the Weather Tool, and the maps of the local average temperature, direct solar radiation and wind frequency and wind speed in December were obtained. Based on this, the Optimum Orientation of the building suitable for local lighting was calculated: about $15^{\circ}$ south by east (Figure 3 ). The two results are basically the same, so as to determine the orientation of the building as $0^{\circ}$ to $15^{\circ}$ south by east is the best range.

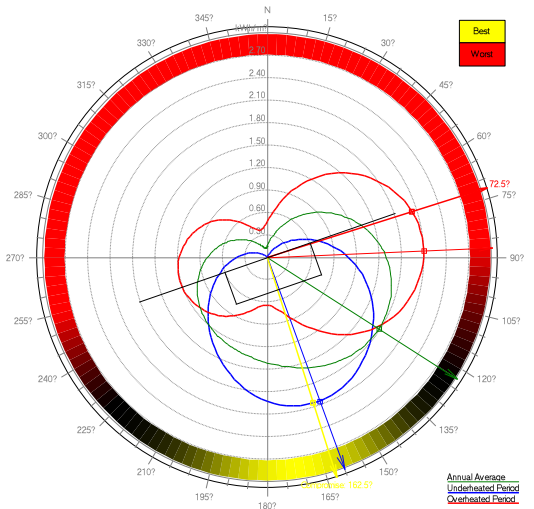

Figure 3. Optimum Orientation analysis

\subsection{Architectural form generation}

\subsubsection{Spatial form and function configuration.}

The layout adjustment (plane) takes the traditional introverted courtyard as the basic unit to ensure the coherence of the overall texture, and forms a more open courtyard and semi-open space to adapt to diverse functional types and enhance the microclimatic environment by way of addition, subtraction and dislocation of the volumes. And the "sunshine gallery" on the second floor is also established to improve the overall lighting, heat gain and loss, and natural ventilated environment of the building. More characteristic functions are considered, such as outdoor lounge (market), folk performance zone, semi-open stage, history and culture zone, etc., to solve the problems of reduced types of public space in settlements and weakened cultural characteristics.

\subsubsection{The roof form.}

The pitched roofs and courtyard forms of the surrounding 
traditional buildings become the inspiration points for the renewal of the architectural form. On the one hand, the pitched roof is the most direct form of traditional inheritance. On the other hand, the pitched roof itself has its advantageous ecological and energy-saving characteristics. Through the analysis of the data of solar direct heat power obtained from the exterior surface of buildings with different roof forms, it is realized that the pitched roof, due to less horizontal plane, is very beneficial to reduce the roof's absorption of direct sunlight heat work and effectively reduce the influence of sunshine on indoor temperature in summer. It also increases the surface's absorption of sunlight in winter.

\subsubsection{The structure and material.}

With reference to the local traditional structure of lifting beams, and considering the combination and flexibility of different materials adapting to a variety of communities, cultures and needs. The light steel structure system was introduced which is more open ${ }^{[10]}$. The structure consists of steel members or Concrete Filled Steel Tubular (CFST) members that is light and thin, good rigidity, easy to process and transport, renewable and reusable, low carbon and environmental in line with the strategy of sustainable development. The local rammed earth and grey tiles combining with the plain and coarse concrete blocks, bricks, cement tiles and other modern materials as the maintenance structural material is selected to form the traditional style. And the reinforced gypsum and polystyrene board is used on the inside of the wall by attaching the insulation material and increasing the thickness of the wall to enhance the thermal insulating properties of the wall (Figure 4).

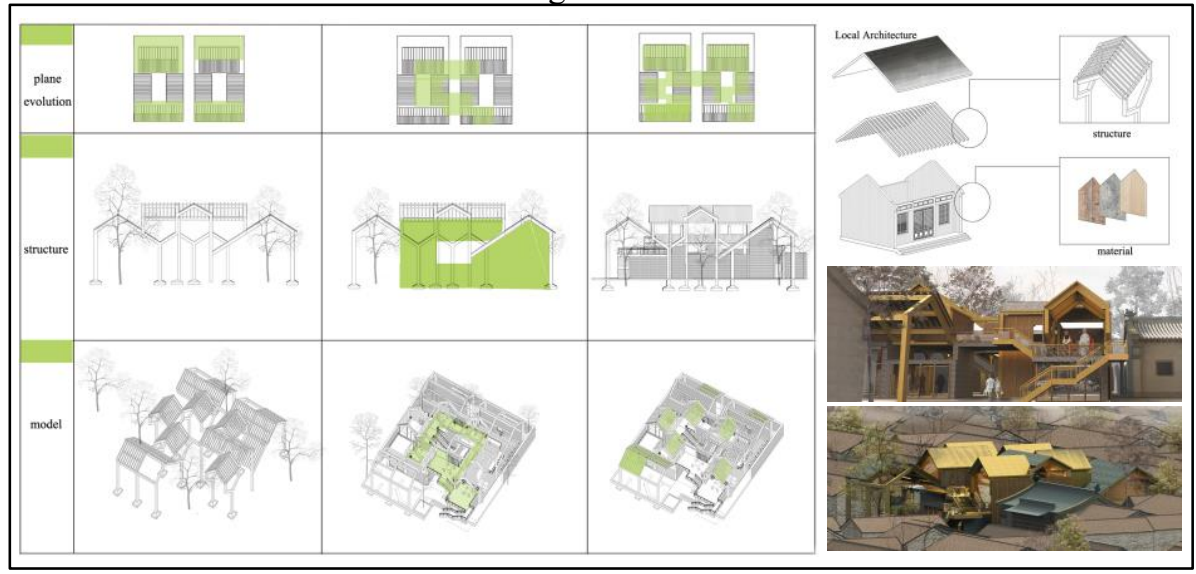

Figure 4. The spatial renewal strategy and design sketch

\subsection{The analysis of microclimatic environment}

Building microclimate analysis mainly include: thermal, light and wind environment ${ }^{[11]}$. Using Ecotect software to preliminary scheme from comfort, daylighting, wind environment and the incident radiation were analyzed, and the results show that the whole building micro-climate performance has greatly improved than the traditional architecture. The indoor can obtain more sufficient light and comfortable heat. The overall ventilation performance is in the middle value, which plays a role in regulating the micro-climate inside the building (Figure 5).

The different elements such as courtyard, corridor and roof formed different elevations in the vertical direction.

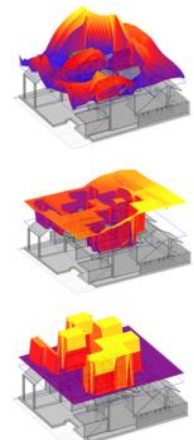

(a) comfort

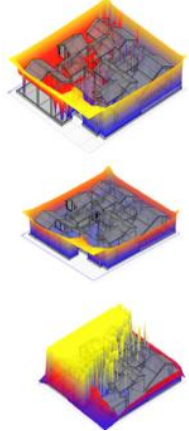

(b) day lighting

The pressure difference between hot and cold airflow forms inside the building, which drives the natural flow of air. The openings of courtyards, windows and roofs are oriented towards the south-westerly winds that is the summer prevailing wind in summer, accelerating the flow of indoor air. In addition, an opening is set in the negative pressure area of the roof's leeward to absorb wind and enhance air flow and exchange. The wind environment simulation plug-in of Ecotect software was used to conduct WINAIR(CFD) analysis of the building, and the results showed that the ventilation effect was good, the wind pressure was maintained between -3.00 and $2.00 \mathrm{~Pa}$, and the change curve was relatively gentle with a small range and relatively comfortable (Figure 6).

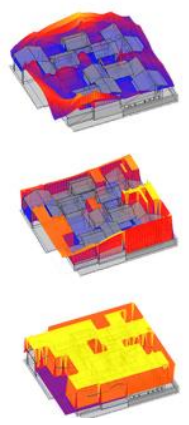

(c) wind environment

(c) wind enviro
formance analysis

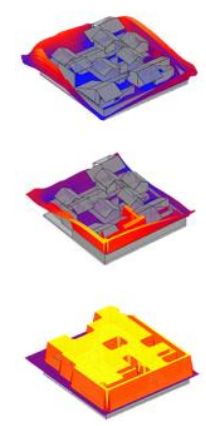

(d) incident radiation 


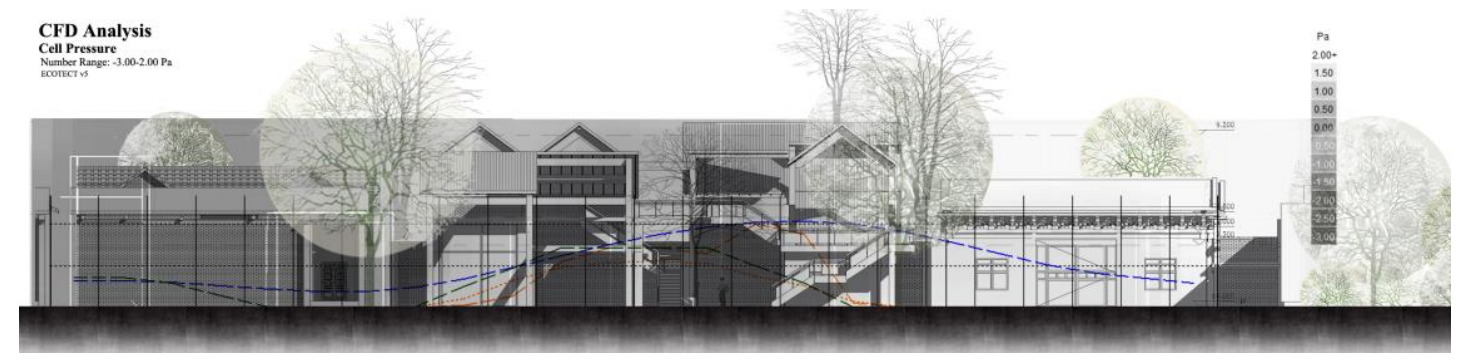

Figure 6. Wind pressure analysis

\section{Conclusions: Design Strategy}

With increasingly severe environmental problems, more and more attention to humanistic spirit and the rapid development of digital technology nowadays, the reconstruction of historical sites should not only inherit traditional features. We also should focus on improving microclimate quality and exploring the close relationship between traditional forms and technological logic, so as to effectively improve the environmental quality. The design strategies to renew the public spaces (building) are mainly reflected as follows:

(1) With the development of social form and economy, the amount of public space in traditional settlements has been greatly reduced, and the types tend to be single. Spiritual space has disappeared, and cultural memory and historical characteristics have been ignored, which can no longer meet the spiritual needs of villagers. Therefore, in the renewal design of public space, it is necessary to inherit the original spiritual attributes and rich space activities.

(2) The courtyards and inner corridors in traditional courtyards not only have cultural connotations, but also have good cooling and ventilation effects. They should be inherited as far as possible in the renewal of the building. And ECOTECT software can be used to improve the lighting and comfort of traditional buildings in microclimate environment.

(3) Combined with the field research data of the current regional culture and the ecological simulation of Ecotect analysis software, the updated building is designed and predicted rationally from both qualitative and quantitative aspects, so as to make the research more convincing. It can be used as a reference to judge and optimize the design of other buildings in the historic town.

\section{Acknowledgement}

This research is supported by the Special Research Projects of the National Natural Science Foundation of China (51708449).

\section{References}

1. Guo, W., Pan, F., Liu, H. (2006) The Leading Role of Government in Developing Ancient Village Tourism From the Perspective of Economics. Commercial Research, 22:192.-195.

2. Jenkins, P., Smith, H., Wang, Y.P. (2007) Planning and Housing in the Rapidly Urbanising World.
Routledge, London.

3. Zheng, Y, Wei, K. (2013) Literature Review of Village Public Space. Huazhong Architecture, 03: 135-139.

4. Li, Y. Bao, J. He, M.Y. (2014) Application research of ECOTECT in residential estate planning. Energy and Buildings, 72(4): 195-202.

5. Xue, Y.S. (2004) The Hancheng Ancient City. Cultural And Historical Records Committee of Hancheng, Hancheng.

6. Zhou, R.Q. Zhang, G. (1999) The Village and Stockade in Hancheng and Dwellings of Dangjia Village. Shaanxi Science And Technology Press, Xi'an.

7. Wang, X.Z. (2019) Models of Conservation and Regeneration of Historic Settlements Based on Public Open Space:a case study on Luocheng ancient town. Modern Urban Research. 06:128-132.

8. Wang, Z.K. Wu, J.J, Wang X.F. (2011) Analysis of Micro Climate Regulation Construction - The First Green Building Design Competition Work. Chinese and Foreign Architectural. 12: 65-67.

9. Sodha, M.S. Kaur, J.G. Sawhney, R.L. (1992) Effect of Orientation on Thermal Performance of a Building. International Journal of Energy Research, 16(8): 709715 .

10. Huang, Z.J. (2007) Hsieh Ying-chun's Rural Architecture Practice of Steel Construction. New Architecture. 04: 8-11.

11. Fan, R.B. Li, H.Y. Yuan D. (2016) Research on Ecological Micro-climate in Historic District Based on Ecotect: the case of Sanxuejie Historic District in Xi'an. Huazhong Architecture, 34(06): 100-105. 